\title{
APOE promoter polymorphisms do not confer independent risk for Alzheimer's disease in a French population
}

Laurence Zurutuza ${ }^{1}$, Patrice Verpillat ${ }^{2}$, Gregory Raux $^{1}$, Didier Hannequin ${ }^{1}$, Michèle Puel $^{3}$, Serge Belliard ${ }^{4}$, Agnès Michon ${ }^{5}$, Yolaine Pothin ${ }^{6}$, Agnès Camuzat ${ }^{6}$, Christiane Penet ${ }^{6}$, Cozette Martin $^{1}$, Alexis Brice ${ }^{6}$, Dominique Campion ${ }^{1}$, Françoise Clerget-Darpoux ${ }^{2}$ and Thierry Frebourg ${ }^{1}$

${ }^{1}$ Faculté de Médecine et de Pharmacie, IN SERM EPI 9906, IFRMP, Rouen; ${ }^{2}$ IN SERM U155, Bois de Boulogne, Paris;

${ }^{3}$ Service de N eurol ogie, Hôpital Purpan, Toulouse; ${ }^{4}$ Service de N eurologie, Hôpital de Pontchaillou, Rennes;

${ }^{5}$ Fédération de N eurologie, Paris; ${ }^{6}$ IN SERM U289, Hôpital de la Sal pêtrière, Paris, France

The apolipoprotein E (APOE, gene; apoE, protein) isoforms are associated with differential risk of Alzheimer's disease (AD). An additional involvement of APOE promoter polymorphisms in AD risk has recently been suggested by several studies. Indeed, three polymorphisms of the APOE regulatory region (-219 G/T, $-427 \mathrm{C} / \mathrm{T}$ and $-491 \mathrm{~A} / \mathrm{T})$ have been found associated with $A D$ even after adjustment on the apoE status. We analysed these three promoter region polymorphisms in a large French case-control study ( $388 \mathrm{AD}$ cases and 386 controls). We found that the $-427 \mathrm{~T}$ and $-491 \mathrm{~A}$ alleles were associated with an increased risk of developing AD, but not the $-219 \mathrm{G} / \mathrm{T}$ alleles. However, a strong linkage disequilibrium was observed between the alleles of these promoter region polymorphisms and the APOE coding region alleles. We therefore retested association after adjustment on apoE status and found that the sole association which remained significant was the association with the $-427 \mathrm{~T}$ allele. The $\alpha$ level was equal to $0.03(0.09$ after Bonferroni correction for multiple comparisons). Analysis of promoter haplotypes also yielded non-significant results. Thus our study does not reinforce the hypothesis of an independent involvement of the APOE promoter region polymorphisms in AD risk. European Journal of Human Genetics (2000) 8, 713-716.

Keywords: Alzheimer's disease; APOE; promoter; linkage disequilibrium

Since the initial report of an association between late-onset Alzheimer's disease (AD) and the apolipoprotein E (APOE, gene; apoE, protein) $\varepsilon 4$ allele, ${ }^{1}$ more than 100 association studies have established the involvement of APOE in AD. Carrying an $\varepsilon 4$ allele increases the risk of $A D$ in an allele dose manner: a meta-analysis found that the odds ratio (OR) is 3.2 (95\% Cl [2.8-3.8]) for individuals with one $\varepsilon 4$ allele and 14.9 (95\% Cl [10.8-20.6]) for those homozygous for the $\varepsilon 4$ allele. ${ }^{2}$ The impact of the $\varepsilon 4$ allele is present in early as well as in lateonset $A D$, but is highest between ages 60 and $80 .^{2,3}$

The presence of an APOE $\varepsilon 4$ allele is neither sufficient nor essential for the development of AD. Other factors (genetic and/or environmental) should interact with the APOE geno-

Correspondence: D Campion, INSERM EPI 9906, Faculté de Médecine et de Pharmacie, IFRMP, 76031 Rouen, France. Tel: +33288 81 82;

Fax: +3323288 80 80; E-mail: Dominique.Campion@univ-rouen.fr Received 9 December 1999; revised 13 April 2000; accepted 18 April 2000 type to determine the risk of AD. Recently it has been suggested that polymorphisms located in the regulatory region of the APOE gene could confer a risk of $A D$, even after adjustment on the apoE status. Three polymorphisms located respectively at $-219 b p$ (Th1/E47cs), $-427 b p$ and $-491 b p$ of the transcriptional start site have been described. These biallelic polymorphisms are: $-219 \mathrm{G} / \mathrm{T}^{4,5}-427 \mathrm{C} / \mathrm{T}^{5,6}$ and $491 \mathrm{~A} / \mathrm{T}^{5-14}$ and the at-risk alleles for $A D$ are $-219 \mathrm{~T},-427 \mathrm{C}$ and $-491 \mathrm{~A}$. For two promoter polymorphisms (-427 and -491), al lelic variants have been coupled with a reporter gene and transfected in astrocytic cells showing that haplotypes associated with the risk of $A D$ are also associated with a higher transcription activity. ${ }^{6}$ Therefore, an increase in expression of APOE could be the physiological mechanism responsible for the allelic association between the promoter region polymorphisms and $A D$. This conclusion is supported by the demonstration that subjects homozygous for the at-risk allele at the -491 locus (-491 AA) have increased 
plasma apoE levels. ${ }^{8}$ In contrast, the biological effect of the -219 allel es is controversial: Artiga et al ${ }^{15}$ have shown that, in hepatoma cells, the $T$ to $G$ substitution provoked an increase in promoter activity whereas Lambert et $\mathrm{al}^{5}$ have reported some evidence that the $T$ allele may increase the relative expression of the APOE $\varepsilon 4$ allele in AD. A close examination of the data shows that for each polymorphism, the allelic association is inconstant among studies. The present study was undertaken to evaluate the role of the APOE promoter region, conditional on the presence of different apoE isoforms, in a large French population of 388AD cases and 386 controls.

\section{Materials and methods Populations}

All subjects enrolled in this study were Caucasian living in France. Unrelated AD patients were ascertained over a 5-year period through consecutive admissions in several university hospitals in France. The diagnosis of probable AD was established according to the criteria of NINCDS-ADRDA. ${ }^{16}$ Age at onset was defined as the age at which the patient or his family first noticed the symptoms required for the diagnosis. Patients belonging to families characterised by autosomal dominant inheritance of an $A D$ gene with complete penetrance by age 60 were excluded from the analysis. In all, $388 \mathrm{AD}$ patients were finally included $(40.7 \%$ men; age at onset $=65.4 \pm 9.4$ years, range [40-90]).

Patients were compared with an age and sex-matched control sample. All controls were screened for cognitive functions. None of them showed symptoms of dementia. A total of 386 control subjects was included $(45.6 \%$ men; age at examination $=66.9 \pm 10.4$ years, range [43-92]). Informed consent was obtained for each subject either directly or from a legal representative. The age and gender distributions did not differ significantly between $A D$ patients and controls ( $P=0.06$ and $P=0.17$, respectively).

\section{Genetic analysis}

DNA was extracted from blood lymphocytes using standard methods. APOE genotypes were determined by restriction enzyme digestion. ${ }^{17}$ The -491 and -427 genotypes were determined by nested PCR and double digestion by Dral and Alul restriction enzymes, as described. ${ }^{6}$ The -219 genotype was determined by PCR using a forward mismatched primer as described by Lambert et al. ${ }^{4}$ To enhance the specificity of the $P C R$ reaction the reverse primer was redesigned as follows: 5'AGGATCCCAGACTTGTCCAATTATA3'. PCR reactions were performed in a total volume of $50 \mu$ l containing 1.30U Taq DNA polymerase, $2 \mathrm{~mm} \mathrm{MgCl}_{2}, 200 \mu \mathrm{M}$ dNTP and $0.2 \mu \mathrm{M}$ of each primer. The PCR consisted of 40 cycles of $30 \mathrm{~s}$ at $94^{\circ} \mathrm{C}, 30 \mathrm{~s}$ at $58^{\circ} \mathrm{C}$ and $30 \mathrm{~s}$ at $72^{\circ} \mathrm{C}$, preceded by $2 \mathrm{~min}$ at $94^{\circ} \mathrm{C}$ and followed by $3 \mathrm{~min}$ at $72^{\circ} \mathrm{C}$. The $231 \mathrm{bp}$ PCR product was purified using the Geneclean III kit (BIO 101, Vista, CA, USA) and then digested with $2.5 \mathrm{U}$ of $\mathrm{M}$ val restriction enzyme at $37^{\circ} \mathrm{C}$ overnight. Restriction fragments were separated on a $4 \%$ agarose gel and visualised using Gelstar (FMC BioProducts, Rockland, Maine, USA). The T allele yielded a $49 \mathrm{bp}$ fragment, whereas the $G$ allele yielded two fragments of $31+18 \mathrm{bp}$. Three constant bands of $69 \mathrm{bp}, 60 \mathrm{bp}$ and $53 \mathrm{bp}$ were also observed.

\section{Statistical analysis}

SAS software release 6.12 was used (SAS Institute, Cary, NC, USA). Univariate analysis was performed using a $\chi^{2}$ test or Fisher exact test when necessary. In the multivariate analysis, we coded the gen otypes of each subject as dummy variables according to the tested hypotheses: carrier of at least one $\varepsilon 4$ allele vs non-carrier of $\varepsilon 4$ allele; non-carrier of the $-219 \mathrm{G}$ allele vs carrier of at least one $-219 \mathrm{G}$ al lele: $T$ v v $\mathrm{GG}+\mathrm{GT}$; non-carrier of the $-427 \mathrm{C}$ allele vs carrier of at least one $-427 \mathrm{C}$ allele: TT versus CC +CT; non-carrier of the $-491 \mathrm{~T}$ allele vs carrier of at least one $-491 \mathrm{~T}$ allele: AA vs TT + AT. The effects of these variables on the disease were assessed with a multiple logistic regression model adjusted for age and gender. Odds ratios (OR) are presented with 95\% confidence intervals $(95 \% \mathrm{Cl})$.

Haplotypes were estimated by the $\mathrm{EH}$ program. ${ }^{18}$ This program allows testing for the existence of linkage disequilibrium between the alleles of two or more loci and estimation of haplotype frequencies.

\section{Results}

No deviations from the Hardy-Weinberg equilibrium were observed among controls for any of the polymorphisms. As expected, the presence of at least one $\varepsilon 4$ allele was associated with an increased risk of $A D(O R=4.02$ [95\% Cl, 2.97-5.44]) (data not shown). We first studied the association of each promoter polymorphism with AD (Table1). Compared with controls, AD patients had higher allele frequencies for -219T, $-427 \mathrm{~T}$ and $-491 \mathrm{~A}$, which led to an excess of homozygotes $-219 \pi,-427 \pi$ and $-491 \mathrm{AA}$. Differences in the genotype and allele distributions were significant only for the -427 and -491 polymorphisms. The OR for developing AD in subjects homozygous for the $-427 \mathrm{~T}$ allele was $1.58(95 \% \mathrm{Cl}$, 1.08-2.31), and the $O R$ for developing $A D$ in subjects homozygous for the $-491 \mathrm{~A}$ allele was $1.52(95 \% \mathrm{Cl}$, 1.10-2.09), after adjustment for age and gender (Table2).

We next investigated the existence of linkage disequilibrium between these alleles, and between them and the $\varepsilon 2, \varepsilon 3$ and $\varepsilon 4$ alleles. No linkage disequilibrium was found between the promoter region polymorphisms alleles themselves (data not shown). In contrast, there was significant evidence for a strong linkage disequilibrium between APOE coding region polymorphisms and each of the three promoter polymorphisms. The -219T, $-427 \mathrm{~T}$ and $-491 \mathrm{~A}$ alleles were statistically more frequently associated with the $\varepsilon 4$ allele than with the other APOE alleles $\left(P=6.10^{-9}, P=4.10^{-6}, P=6.10^{-10}\right.$, respectively). To eliminate possible confounding effects due 
Table 1 Distribution of the $-219,-427,-491$ alleles and of the corresponding genotypes in controls and AD patients

\begin{tabular}{lllllr}
\hline \multicolumn{7}{c}{ Allele } & \multicolumn{5}{c}{ Genotype } \\
\hline-219 & G & T & GG & GT & TT \\
Controls & $399(0.52)$ & $373(0.48)$ & $101(0.26)$ & $197(0.51)$ & $88(0.23)$ \\
AD & $373(0.48)$ & $403(0.52)$ & $89(0.23)$ & $195(0.50)$ & $104(0.27)$ \\
-427 & C & $T$ & CC & CT & $\pi$ \\
Controls & $84(0.11)$ & $688(0.89)$ & $5(0.01)$ & $74(0.19)$ & $307(0.80)$ \\
AD & $55(0.07)$ & $721(0.93)$ & $1(\varangle 0.01)$ & $53(0.14)$ & $334(0.86)$ \\
-491 & A & T & AA & AT & T \\
Controls & $635(0.82)$ & $137(0.18)$ & $258(0.67)$ & $119(0.31)$ & $9(0.02)$ \\
AD & $676(0.87)$ & $100(0.13)$ & $295(0.76)$ & $86(0.22)$ & $7(0.02)$ \\
\hline
\end{tabular}

Frequencies are indicated in brackets.

Table 2 Adjusted OR estimated by multivariate logistic regression

\begin{tabular}{llll}
\hline OR [95\% Cl] & -219 & -427 & -491 \\
& TT vs GG + GT & TT vs CC + CT & AA vs TT + AT \\
\hline Adjusted for age and gender & 1.23 & $1.58^{*}$ & $1.52^{*}$ \\
& {$[0.88-1.70]$} & {$[1.08-2.31]$} & $1.10-2.09]$ \\
& 0.96 & $1.56 *$ & 1.22 \\
$\begin{array}{l}\text { Adjusted for age, gender and } \\
\text { including the three promoter } \\
\text { polymorphisms and apoE status }\end{array}$ & {$[0.68-1.39]$} & {$[1.04-2.34]$} & {$[0.87-1.71]$} \\
\hline
\end{tabular}

$* \mathrm{P} \varangle 0.05 ; 95 \% \mathrm{Cl}$ is indicated in brackets.

Table 3 Distribution of haplotypes $\mathrm{H} 1, \mathrm{H} 2$ and $\mathrm{H} 3$ in controls and AD cases (1), conditionally to the APOE $\varepsilon 4$ (2) and $\varepsilon 3$ (3) alleles

\begin{tabular}{lllll}
\hline & Haplotypes & Controls & AD cases & P \\
\hline (1) & H1 & $293(0.379)$ & $302(0.389)$ & 0.0008 \\
& H2 & $273(0.354)$ & $326(0.420)$ & \\
& & $206(0.267)$ & & 0.43 \\
$(2)$ & $\varepsilon 4-\mathrm{H} 1$ & $34(0.306)$ & $148(0.191)$ & \\
& $\varepsilon 4-\mathrm{H} 2$ & $70(0.631)$ & $29(0.101)$ & 0.13 \\
& $\varepsilon 4-\mathrm{H} 3$ & $7(0.063)$ & $227(0.487)$ & \\
$(3)$ & $\varepsilon 3-\mathrm{H} 1$ & $258(0.432)$ & $142(0.305)$ & \\
& $\varepsilon 3-\mathrm{H} 2$ & $188(0.315)$ & $97(0.208)$ & \\
& $\varepsilon 3-\mathrm{H} 3$ & $151(0.253)$ & & \\
\hline
\end{tabular}

Frequencies are indicated in brackets; distribution of haplotypes differs significantly between controls and AD cases ( $\left.\chi^{2}, 2 \mathrm{df}\right)$; distributions of haplotypes between controls and AD cases conditionally to the APOE $\varepsilon 4$ or APOE $\varepsilon 3$ allele are no more significantly different.

to this linkage disequilibrium, we performed a multivariate logistic regression including the three promoter polymorphisms and the APOE genotype in the same model, in addition to age and gender. After adjustment, the sole association which remained significant was that with the -427T polymorphism (Table2). When a Bonferroni correction for multiple comparisons was performed, this association of the $-427 T$ allele with $A D$ did not reach the significance level. The corrected significance level was 0.09 and the $\mathrm{Cl}$ of the OR was [0.95-2.56] for a corrected $\alpha$ level equal to $0.05 / 3$ (three test were realised at the final stage of the logistic regression analysis).

We then considered the promoter polymorphisms as a single haplotype including three DNA markers at position
$-219,-427$ and -491 . Since only two haplotypes were frequent in controls, we decided to merge the other six into one single class. The three promoter polymorphisms were thus considered as a marker $\mathrm{H}$ of the APOE promoter with three haplotypes. The most frequent haplotype (-219G--427T--491A) was named $\mathrm{HI}$, the second (-219T--427T--491 A) H2 and the last H3. The distribution of these three haplotypes differed significantly between cases and controls ( $\mathrm{P}=0.0008$ ) (Table 3 ). The haplotypes $\mathrm{H} 1$ and $\mathrm{H} 2$ were associated with an increased risk of $\mathrm{AD}$ when $\mathrm{H} 3$ was taken as a reference $(\mathrm{OR}[\mathrm{H} 1$ vs $\mathrm{H} 3]=1.44,95 \% \mathrm{Cl}$ [1.10-1.87]; OR[H2 vsH3] = 1.66, 95\% Cl [1.28-2.17]). When the haplotypes distribution was stratified according to the APOE alleles, the difference between cases and controls was 
no more statistically significant, either between the $\varepsilon 4$ allele AD cases and controls $(P=0.43)$, or between the 83 AD cases and controls $(P=0.13$ ) (Table 3$)$.

\section{Discussion}

In our study, one of the three promoter region polymorphisms $(-219 \mathrm{G} / \mathrm{T})$ showed no allelic association with $A D$ even after adjustment on age, gender and apoE status. This result is consistent with those of Artiga et al, ${ }^{6}$ who had found no significant association between the -219 polymorphism and risk of $A D$, but not with those of Lambert et al., ${ }^{4,5}$ Concerning this polymorphism, we have calculated that our sample had near $98 \%$ power to detect an effect of size equivalent to that reported by Lambert et al. ${ }^{4}$ The lack of association in our sample compared with that of Lambert et al is explained both by an increase of the $G$ allele in patients and by a decrease in controls in the present study. Nevertheless, we confirm the strong linkage disequilibrium, found by Lambert et $\mathrm{al}^{4}$ between the -219 alleles and the APOE coding region alleles.

Our results concerning the -491 polymorphism perfectly match those obtained by Lambert et al in a French population: the risk associated with the $-491 \mathrm{~A}$ allele is not independent of the apoE status. ${ }^{5,13}$ The only factor conferring an additional risk of $A D$, even after adjustment for the apoE status, is the -427 T allele. Lambert et al also observed a trend toward an excess of the T allele in their French sample, although this trend did not reach statistical significance. ${ }^{5}$ This result is unexpected since the allele conferring a higher transcriptional activity is the $C$ allele, which was associated with $A D$ in the Spanish population. ${ }^{6}$ Thus, the allelic association with the-427T allele is difficult to reconcile with the biological role assigned to this allele and we prefer the alternative explanation that the $-427 \mathrm{~T}$ allele is not functionally related to the additional risk of $A D$ but is instead in linkage disequilibrium with a putative causative factor. Finally, no result remained statistically significant after the Bonferroni correction, the drastic effects of which are well known. It should be emphasised that no attempt to correct for multiple testing was made in other studies. ${ }^{4,6,7}$ In order to circumvent the problem posed by correction for multiple testing (which could lead to false negative results), we then analysed the three promoter polymorphisms as a single haplotyped marker with three alleles. Thus the number of tests was reduced and the study had more power to detect a possible role of the APOE promoter. However this approach also yielded negative results. We conclude that our results do not support the existence of an independent risk of $A D$ conferred by APOE promoter polymorphisms.

\section{Acknowledgements}

We thank the Etablissement de Transfusion Sanguine de Haute-Normandie for its participation in this study and Vincent Bagard for his critical reading of the manuscript. PV is the recipient of a fellowship from the Fondation pour la Recherche Médicale. LZ and PV contributed equally to this work.

\section{References}

1 Saunders AM, Strittmatter WJ, Schmechel D et al: Association of apolipoprotein E allele $\varepsilon 4$ with late-onset familial and sporadic Alzheimer's disease. Neurology 1993; 43: 1467-1472.

2 The APOE and Alzheimer Disease Meta-Analysis Consortium: Effects of age, gender and ethnicity on the association between apolipoprotein E genotype and Alzheimer disease. A metaanalysis. J Am Med Assoc 1997; 278: 1349-1356.

3 Bickeböller H, Campion D, Brice A et al: Apolipoprotein E and Alzheimer disease: genotype-specific risks by age and sex. Am J Hum Genet 1997; 60: 439-446.

4 Lambert J-C, Pasquier F, Cottel D, Frigard B, Amouyel P, and Chartier-Harlin MC: A new polymorphism in the APOE promoter associated with risk of developing Alzheimer's disease. Hum Mol Genet 1998; 7: 533-540.

5 Lambert JC, Berr C, Pasquier F et al: Pronounced impact of Th1/E47cs mutation compared with -491 AT mutation on neural APOE gene expression and risk of developing Alzheimer's disease. Hum Mol Genet 1998; 7: 1511-1516.

6 Artiga MJ, Bullido MJ, Frank A et al: Risk for Alzheimer's disease correlates with transcriptional activity of the APOE gene. Hum Mol Genet 1998; 7: 1887-1892.

7 Bullido MJ, Artiga MJ, Recuero M et al: A polymorphism in the regulatory region of APOE associated with risk for Alzheimer's dementia. Nat Genet 1998; 18: 69-71.

8 Laws SM, Taddei K, Martins G et al: The-491 AA polymorphism in the APOE gene is associated with increased plasma ApoE levels in Alzheimer's disease. Neuroreport 1999; 10: 879-882.

9 Town T, Paris D, Fallin D et al: The $-491 \mathrm{~A} / \mathrm{T}$ apolipoprotein E promoter polymorphism association with Alzheimer's disease: independent risk and linkage disequilibrium with the known APOE polymorphism. Neurosci Lett 1998; 252: 95-98.

10 Toji H, Maruyama H, Sasaki K, Nakamura S, Kawakami H: Apolipoprotein E promoter polymorphism and sporadic Alzheimer's disease in a Japanese population. Neurosci Lett 1999; 259: 56-58.

11 Roks G, Cruts M, Bullido MJ et al: The $-491 \mathrm{~A} / \mathrm{T}$ polymorphism in the regulatory region of the apolipoprotein $\mathrm{E}$ gene and early-onset Alzheimer's disease. Neurosci Lett 1998; 58: 65-68.

12 Ahmed AR, MacGowan SH, Culpan D, Jones RW, Wilcock GK: The $-491 \mathrm{~A} / \mathrm{T}$ polymorphism of the apolipoprotein $\mathrm{E}$ gene is associated with the ApoE epsilon4 allele and Alzheimer's disease. Neurosci Lett 1999; 263: 217-219.

13 Casadei VM, Ferri C, Veglia F et al: APOE -491 promoter polymorphism is a risk factor for late-onset Alzheimer's disease. Neurology 1999; 53: 1888-1889.

14 Helisalmi S, Hiltunen M, Valonen $P$ et al: Promoter polymorphism $(-491 \mathrm{~A} / \mathrm{T})$ in the APOE gene of Finnish Alzheimer's disease patients and control individuals. J Neurol 1999; 246: 821-824.

15 Artiga MJ, Bullido MJ, Sastre I et al: Allelic polymorphisms in the transcriptional regulatory region of apolipoprotein E gene. FEBS Letters 1998; 421: 105-108.

16 McKahn G, Drachman D, Folstein M, Karzman R, Price D, Stadlan E: Clinical diagn osis of Alzheimer's disease: report of the NINCDSADRDA work group. Neurology 1984; 34: 939-944.

17 Hixon JE, Vernier DT: Restriction isotyping of human apolipoprotein $\mathrm{E}$ by gene amplification and cleavage with Hhal. J Lipid Res 1991; 31: 545-548.

$18 \mathrm{XieX}, \mathrm{Ott}$ J: Testing linkage disequilibrium between a disease gene and marker loci. Am J Hum Genet 1993; 53: 1107. 